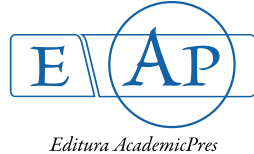

Editura AcademicPres

\title{
Usefulness of a Locus LE21085 in the Genetic Differentiation of Tomato Varieties
}

\author{
Elizabeta MISKSOKA-MILEVSKA*, Zoran T. POPOVSKI, \\ Tome NESTOROVSKI
}

University Ss. „Cyril and Methodius” in Skopje, Faculty of Agricultural Sciences and Food, Blvd. Aleksandar Makedonski b.b. 1000 Skopje, Republic of Macedonia; miskoska@yahoo.com (*correspondingauthor); zoran_popovski@yahoo.com;tome_357@hotmail.com

\begin{abstract}
The microsatellites are specific for each individual genome or species. In order to evaluate the genetic diversity and the relationships within the genus Lycopersicon microsatellites markers were used. The main objective of this study was to determine the usefulness of the locus LE21085 in the genetic differentiation among six morphologically different tomato varieties of Lycopersicon esculentum Mill. (var. grandifolium subsp. cultum; var. cerasiforme - red and yellow, var. pruniforme, var. pyriforme subsp. subspontaneum, and var. racemigerum subsp. spontaneum). For the microsatellites locus LE21085 were detected two alleles in all estimated tomato varieties, that differed by one base pair (122 and $123 \mathrm{bp}$ ). The biggest allele frequency was found for the allelic variant of $122 \mathrm{bp}$, and its values were: 0.8462 for L. esculentum subsp. subspontaneum var. cerasiforme (red), 0.6923 for L. esculentum subsp. subspontaneum var. cerasiforme (yellow), 0.5769 for L. esculentum subsp. cultum var. grandifolium, 0.6923 for L. esculentum subsp. subspontaneum var. pruniforme, 0.6154 for L. esculentum subsp. subspontaneum var. pyriforme and 0.8077 for L. esculentum subsp. spontaneum var. racemigerum. The average of observed heterozygosity for the locus LE21085 ( $\mathrm{Ho}=0.5641$ ) was higher than average expected heterozygosity $(\mathrm{He}=0.4158)$. The average PIC value for the locus LE2 1085 was 0.3294 and it was classified as a modest informative markers. From the obtained results it can be concluded that locus LE2 1085 could be used in genetic differentiation of tomato varieties, but in combination with other polymorphic microsatellite loci.
\end{abstract}

Keywords: DNA microsatellites, fragment analyses, locus LE21085, tomato

\section{Introduction}

Molecular markers have many advantages for plant variety identification over the more traditionally used morphological traits because of their independence from environmental influences, their generally high level of polymorphism, their almost unlimited availability, and their greater potential for automation (Bredemeijer et al., 2002). Molecular techniques are also likely to be extremely discriminating and much more rapid (Vosman et al., 2001). Genotypic differences detected by molecular markers can be used for cultivar identification and protection of the plant breeder's intellectual property rights (Garcia-Martinez et al., 2006). According to Miller and Tanksley (1990) the molecular marker of choice must be very informative, especially in crop like tomato where genetic diversity is very limited (Bredemeijer et al., 2002).

The microsatellites, also called simple sequence repeats (SSRs) appear as suitable molecular markers because of their highly polymorphic character. SSR markers have the advantages of being multiallelic, highly polymorphic, codominant and assayable by PCR. The first application of SSR markers in plants has been in cultivar identification. Around 1.4 million STRs were generated from tomato genome (Iquebal et al., 2013). Microsatellites are useful for a number of analyses. The SSRs play significant role in mapping variety development, trait improvement and variety identification. According to $\mathrm{He}$ et al. (2003) microsatellite markers were demonstrated to be highly polymorphic and efficient for differentiating genetic materials, further suggesting their capacity for practical application in cultivar and seed purity identification and phylogenetic study. The enlightening, of microsatellites, as a genetic marker has already been shown with great success in several plant species (Alvarez et al., 2001). A significant role of microsatellite markers in research of genetic diversity and variability of genus Solanum, as well as for tomato variety identification was confirmed in many studies (Smulders $e t$ al., 1997; Bredemeijer et al., 2002; He et al., 2003; Villalta $e t$ al., 2005; Garcia-Martinez et al., 2006; Mazzucato et al., 2008). SSR markers are becoming the preferred molecular 
210

marker for variety identification, genetic mapping and marker-assisted selection in tomato (He et al., 2003). According to Smulders et al. (1997), the level of polymorphism and the scorability of the banding patterns are important when choosing new microsatellite loci for identification purposes or for studies on genetic variation. The allelic variation may be correlated with the number of repeats within a particular microsatellite locus ( $\mathrm{He} e t$ al., 2003).

The informative amount of polymorphic DNA markers can be quantitatively measured statistically by means of the polymorphism information content (PIC). Selected molecular markers must be very informative especially for crops like Lycopersicon esculentum, where genetic diversity seems very limited (Miller and Tanksley, 1990). Such microsatellites may show polymorphisms that can be useful for the analysis of genetic diversity, as well as determination of species relationships within the genus Lycopersicon. The interest for the microsatellite locus LE21085 is presented in the studies of Smulder at al. (1997), Bredemeijer et al. (1998), Alvarez et al. (2001), He et al. (2003), Villata et al. (2005), Garcia-Martinez et al. (2006), Mazzucato et al. (2008).

The main objective of this work was to examine the potential of the locus LE21085 in genetic differentiation among six morphologically different tomato varieties of Lycopersicon esculentum Mill.

\section{Materials and Methods}

\section{Plantmaterial}

In this study, six tomato varieties of Lycopersicon esculentum Mill. (var. grandifolium subsp. cultum; var. cerasiforme - red and yellow, var. pruniforme, var. pyriforme subsp. subspontaneum and var. racemigerum subsp. spontaneum) were analysed. Lycopersicon esculentum var. grandifolium has large, red fruits with flattened shape. Lycopersicon esculentum var. cerasiforme produces small fruits with slightly flattened shape in red or yellow colour. Lycopersicon esculentum var. pruniforme forms small, red or yellow fruits with specific oval (plum) shape. Lycopersicon esculentum var. pyriforme forms pear-shaped small red fruits. Lycopersicon esculentum var. racemigerum is characterized by medium-large fruits with flattened shape in red or yellow colour. The plant material was obtained from the GeneBank of the Agricultural Institute in Skopje.

\section{DNA isolation and PCR conditions}

The DNA isolation and optimization of the PCR conditions were performed in the Laboratory for biochemistry and molecular biology within the Department of Biochemistry and Genetic Engineering at the Faculty of Agricultural Sciences and Food - Skopje (Miskoska Milevskaet al., 2012). The DNA was isolated from fresh leaves using Promega's Wizard ${ }^{\circ} \mathrm{Genomic}$ DNA purification kit. The leaves were collected from ten individual plants per each variety. Also, pooled seeds were used for DNA isolation. The DNA isolation from seeds was done using modified CTAB method (Miskoska-Milevska et al., 2011).
Namely, collected leaves were stored at $-70^{\circ} \mathrm{C}$ till the DNA isolation, even if the step was not part of the protocol. The amount of starting plant material for DNA isolation was 50 $\mathrm{mg}$ instead $10-20 \mathrm{mg}$. To remove RNA it was necessary to be added treatment with RNaze $(10 \mu \mathrm{g} / \mu \mathrm{L})$. Also, phenol/chloroform re-extraction was necessary for obtaining high quality DNA (Miskoska-Milevska et al., 2011). The quality of the isolated DNA was checked by running it on $0.8 \%$ agarose gel. The optimization of the PCR conditions for amplification of the locus LE21085 was performed using appropriate primers, produced by Operon, Huntsville, AL. Some general data for the locus LE21085 and appropriate primer pair are presented in Table 1 (Miskoska-Milevska et al., 2012). Visualization of the PCR products were done by running them on $2 \%$ agarose gel, stained with ethidium bromide and photographed under UV light by using G-Box system (Sygene).

\section{Data analyses}

The fragment analyses of the PCR products were performed on Applied Biosystems DNA analyzer (ABI 3130) using GeneMapper Software program. The specific program Power Marker Software was used for data analyzing.

\section{Results and Discussion}

The analyzed microsatellite primers showed strong amplification within the estimated tomato varieties and were used for the fragment analysis (Fig. 1 and Fig. 2). The data from fragment analysis was presented in the form of electropherograms of heterozygous (Fig. 1) and homozygous samples (Fig. 2). The interpretation of the obtained electropherograms is significant because the further statistical analyses are based on these results. The peaks higher than 100 RFU and lower than 2,000 RFU were taken in consideration.

The fragment analyses of the locus LE21085 detected only two allelic variances (122-123 bp) and their frequencies are shown in Fig. 3. The detected alleles differed by one base pair, as well as in study of Alvarez et al. (2001). Alvarez et al. (2001) noticed 12 different alleles in the researched tomatoes (90-93-96-99-102-105-108-111-118-119-127$132 \mathrm{bp}$ ), and the number of specific alleles was six. According to these researchers, alleles of unexpected sizes occur across the genus. Thus, $31 \%$ of the microsatellites analyzed appear to be concordant with the single-step mutation model and another $31 \%$ possibly follow this model with minor modification, although the presence of these series by itself does not prove that they proceeded by mutation with one repeat unit at a time (Alvarez et al., 2001).

The Stepwise Mutation Model (SMM) implies that an allele mutates only by losing or gaining a single tandem repeat. According to this model, the allele with $i$ repeats are assumed to mutate to an allele either in state $i+1$ or $i-1$ with an equal probability (Ohta and Kimura, 1973). In the present research, it is obviously appearance of alleles that differ in only one base pair (Fig. 1). It can be assumed that appearance of these alleles is in line with Stepwise Mutation Model (SMM) proposed by Ohta and Kimura (1973). 
The knowledge of the mutation process is necessary for understanding the species relationships and for determination of genetic distance or population structure, respectively.

Usually, the assessment of species relationships is based on interpretation of allozyme variations, but IAM-model (Infinite Allele Model) shows as very successful in explanation of alozyme variations (Nei, 1987). The situation is much different for the microsatellite markers. As first, since more of the mutations include receiving or losing one repetitive unit (Weber and Wong, 1993), it is clear that there exists a high amount of homoplasy. This is important as homoplasy leads to the underestimation of the total amount of variation and genetic distance, and to the overestimation of the similarities among populations.

These two models, the IAM and SMM, represent the extremes of the situation. In the IAM no homoplasy exists, while in the SMM, a large amount is present. Microsatellites have been estimated to mutate at rate between $10^{3}$ and $10^{5}$ mutations per gamete (Edwards et al., 1992; Bowcock et al., 1994; Forbes et al., 1995). Empirical data also suggests that the structure of the microsatellite repeat may be very important in determining the operating mutational process (Estoup et al., 1995a, 1995b). Estoup et al. (1995a) examined the variation, found at two loci with irregular microsatellite repeats in bees in order to determinate the levels of homoplasy that exist between populations. Irregular repeats are core repeats that are interrupted by point mutations. The presence of these mutations allows alleles with similar sizes to be distinguished. Not surprisingly, as the taxonomic level of the comparisons increased (i.e. among species), the amount of homoplasy increased.

In this regard it is clear that evolution of microsatellites is a very complex process. More research work is needed in order to completely understand the mutations that are necessary for proper interpretation of microsatellites results.

For locus LE21085, Smulders et al. (1997) detected five different alleles in researched tomatoes, while Villata $e t$ al. (2005) noticed only one allele (130 bp). Four different alleles were detected for same locus in researched tomatoes by Bredemeijer et al. (2002) and Garcia-Martinez et al. (2006). Three alleles were noticed on this microsatellite locus by He et al. (2003) and Mazzucato et al. (2008), while Bredemeijer et al. (1998) found two alleles (103-116 bp).
The differences in allele number and size are evident, between this study and the studies mentioned before. This difference is probable due to the different plant material used in each research. Namely, Bredemeijer et al. (1998) and $\mathrm{He}$ et al. (2003) researched only cultivated tomato accessions, whereas in this study, tomato varieties from subsp. cultum, subsp. subspontaneum and subsp. spontaneum were included. Also, the difference in allele size could be due to the methodological approach. Different DNA analysers, as well and different working conditions on the same DNA analyser (for ex. different type of polymer, different capillary length) could be reason for receiving such differences in allele size. In this regard might be concluded that, working on same DNA analyser with the same working conditions (for ex. same capillary length, same type of polymer) is the best option.

The data presented in Fig. 3 showed that the allelic variances in size of 122 and 123 bp appeared on the locus LE21085 across all analysed varieties.

In the analysed varieties, the biggest allele frequency was found for the allelic variant of $122 \mathrm{bp}$, and its values were: (0.8462) for Lycopersicon esculentum subsp. subspontaneum var. cerasiforme (red), (0.6923) Lycopersicon esculentum subsp. subspontaneum var. cerasiforme (yellow), (0.5769) for Lycopersicon esculentum subsp. cultum var. grandifolium, (0.6923) for Lycopersicon esculentum subsp. subspontaneum var. pruniforme, (0.6154) for Lycopersicon esculentum subsp. subspontaneum var. pyriforme and (0.8077) for Lycopersicon esculentum subsp. spontaneum var. racemigerum.

The average observed heterozygosity for the locus LE21085 $(\mathrm{Ho}=0.5641)$ was higher than average expected heterozygosity $(\mathrm{He}=0.4158)$, meaning increased level of heterogeneity in the researched tomato varieties (Table 2).

The polymorphism information content (PIC) is used to quantitatively measure the informativeness of polymorphic DNA markers. In the analysed tomato varieties, average PIC value for the locus LE21085 was 0.3294 (Table 2). According to the classification of Botstein et al. (1980), this locus belongs to the group of modest informative markers.

The genetic differentiation test $(\theta)$ in the analysed tomato varieties presented minor genetic differentiation for the locus LE21085 (0.0297). Also, this test showed modest differentiation for the locus LE21085 on subspecies level (0.0551) (Miskoska-Milevska et al., 2015).

Table 1. General data for microsatellite locus LE21085 and primers used in this study

\begin{tabular}{ccc}
\hline Locus & Repeat motif & Primer sequences $\left(5^{\prime}-3^{\prime}\right)$ \\
\hline LE21085 & $(\text { TA })_{2}(\text { TAT })_{9-1}$ & $\begin{array}{c}\text { F: M13-cat ttt atc att tat ttg tgt ctt g } \\
\text { R: aca aaa aaa ggt gac gat aca }\end{array}$ \\
\hline (F - Forward primer $\left(5^{\prime}-3^{\prime}\right)$ R - Reverse primer $\left(5^{\prime}-3^{\prime}\right)$ M13 tail: $5^{\prime}$-cac gac gtt gta aaa cga c-3')
\end{tabular}

Table 2. Genetic variability and polymorphism of locus LE21085 in the researched tomato varieties

\begin{tabular}{|c|c|c|c|c|c|}
\hline Locus & Number of genotypes & $\begin{array}{c}\text { Number of } \\
\text { alleles }\end{array}$ & $\mathrm{He}$ & Ho & PIC \\
\hline LE21085 & 3.0000 & 2.0000 & 0.4158 & 0.5641 & 0.3294 \\
\hline
\end{tabular}

He - expected heterozygosity

Ho - observed heterozygosity

PIC - test for determination of informativeness for analysed DNA microsatellite locus 
212

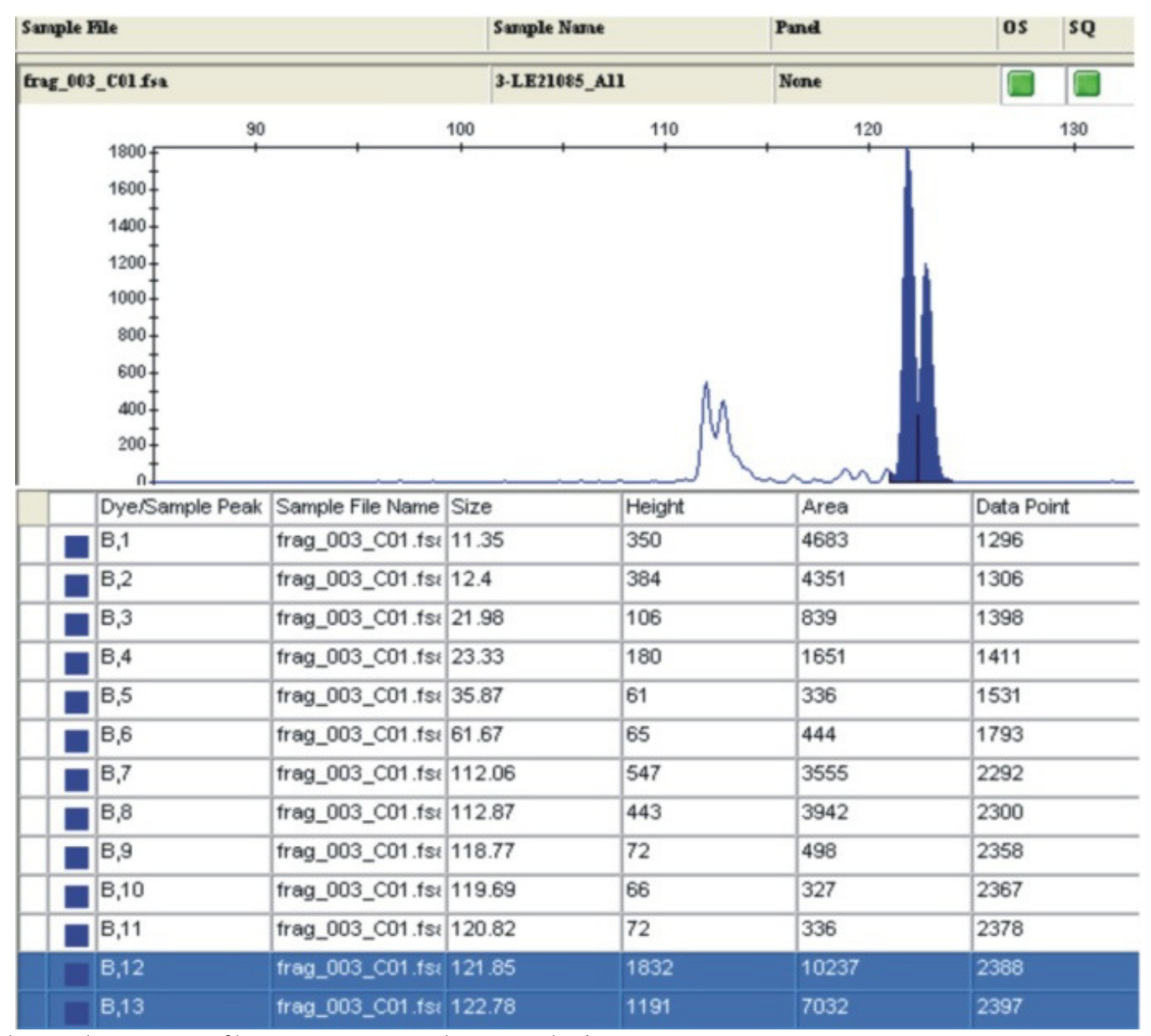

Fig. 1. The electropherograms of locus LE21085 in the researched tomato varieties

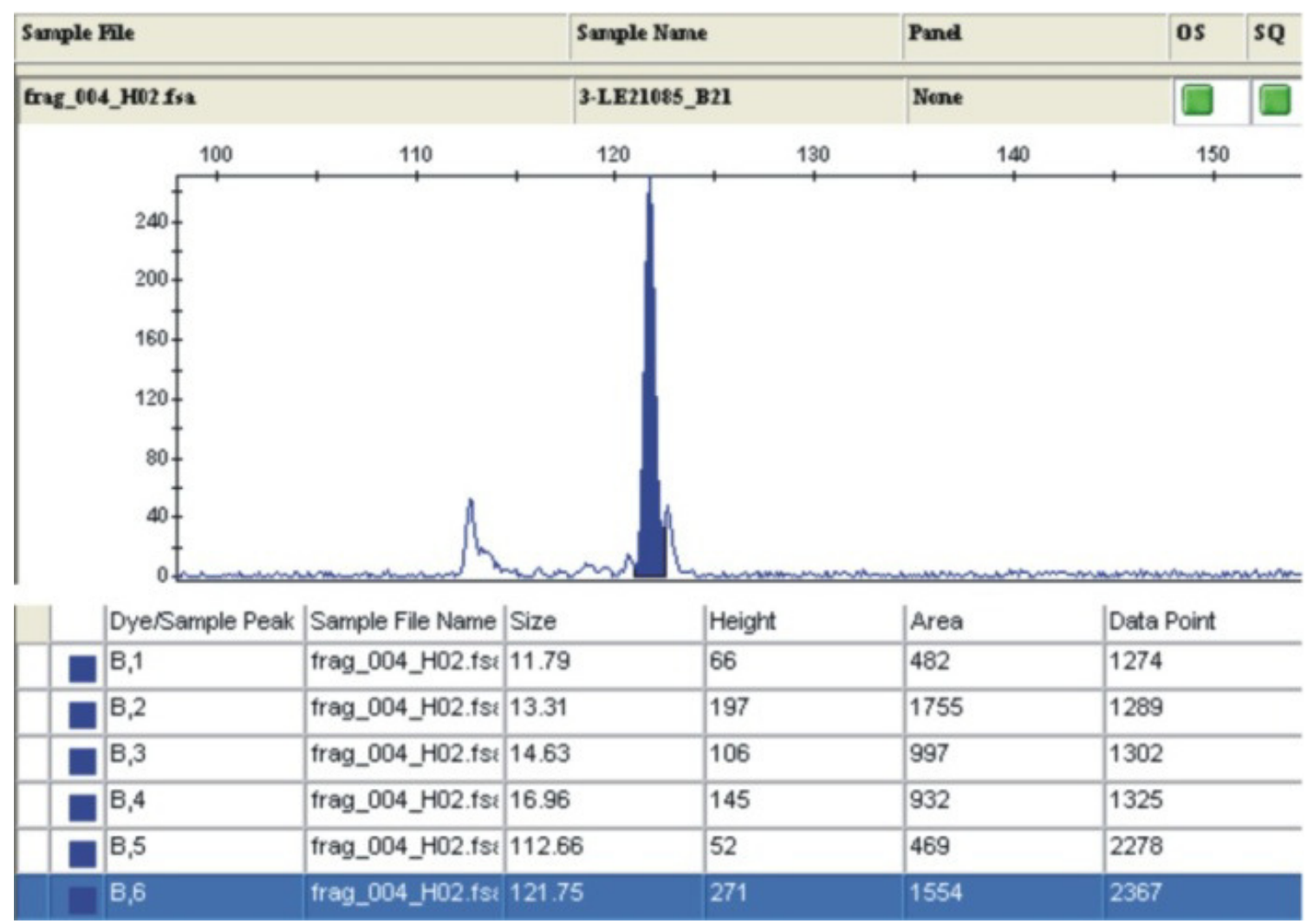

Fig. 2. The electropherograms of locus LE21085 in the researched tomato varieties 


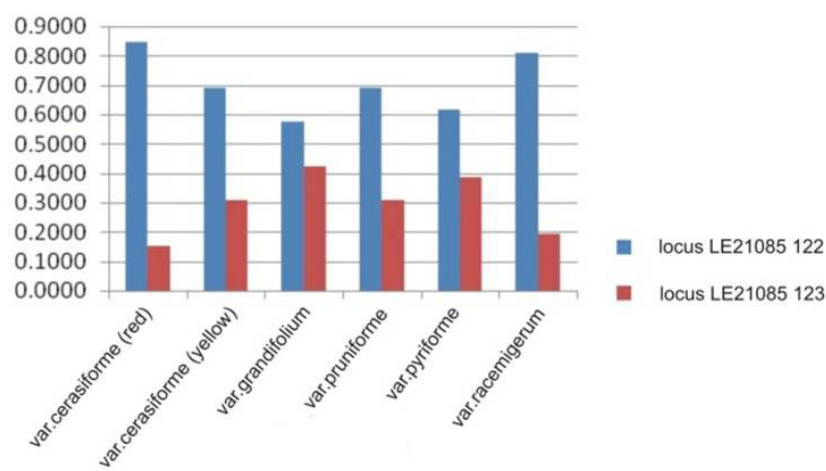

Fig. 3. The allelic variances and their frequencies for locus LE21085 in the researched tomato varieties

\section{Conclusions}

The microsatellite locus achieved amplification across all the six tomato varieties. The detected allelic variances were different by one base pair. For distinguishing the tomato varieties it is necessary, that the locus LE21085 to be combined with other more polymorphic microsatellite loci.

\section{References}

Alvarez AE, Van De Wiel CCM, Smulders MJM, Vosman B (2001). Use of microsatellites to evaluate genetic diversity and species relationships in the genus Lycopersicon. Theoretical and Applied Genetics103:1283-1292.

Botstein D, White RL, Skolinick M, Davis RW (1980). Construction of genetic linkage hjn7u6my map in a man using restriction fragment length polymorphism. American Journal of Human Genetics 32:314-331.

Bowcock AM, Ruiz-Linares A, Tomfohrde J, Minch E, Kidd JR, Cavalli-Sforza LL (1994). High resolution of human evolution with polymorphic microsatellites. Nature 368:455-457.

Bredemeijer G, Cooke R, Ganal M, Peeters R, Isaac P, Noordijk Y, Rendell S, Jackson J, Röder M, Wendehake K, Dijcks M, Amelaine M, Wickaert V, Bertrand L, Vosman B (2002). Construction and testing of a microsatellite database containing more than 500 tomato varieties. Theoretical and Applied Genetics 105 (6-7):10191026.

Bredemeijer GMM, Arens P, Wouters D (1998). The use of semiautomated fluorescent microsatellite analysis for tomato cultivar identification. Theoretical and Applied Genetics 97:584-590.

Edwards A, Hammond HA, Jin L, Caskey CT, Chakraborty R(1992). Genetic variation at five trimeric and tetrameric tandem repeat loci in four human population groups. Genomics 12:241-253.

Estoup A, Tailliez C, Cornuet JM, Solignac M (1995a). Size homoplasy and the mutational processes of interrupted microsatellites in two bee species, Apis mellifera and Bombus terrestrus (Apidae). Molecular Biological Evolution 12:1074-1084.

Estoup A, Garnery L, Solignac M, Cornuet JM (1995b). Microsatellite variation in honey bee populations: Hierarchical genetic structure and test of the IAM and SMM. Genetics 140:679-695.

Forbes SH, Hogg JT, Buchanan FC, Crawford AM, Allendorf FW (1995). Microsatellite evolution in congeneric mammals: Domestic and Bighorn sheep. Molecular Biological Evolution 12:1106-1113.
Garcia-Martinez S, Andreani L, Garcia-Gusano M, Geuna F, Ruiz JJ (2006). Evaluation of amplified fragment length polymorphism and simple sequence repeats for tomato germplasm fingerprinting utility for grouping related traditional cultivars, Genome 49:648-656.

He C, Poysa V, Yu K (2003). Development and characterization of simple sequence repeat (SSR) markers and their use in determining relationships among Lycopersicon esculentum cultivars. Theoretical and Applied Genetics 106(2):363-373.

Iquebal MA, Sarika, Arora V, Verma N, Rai A, Kumar D (2013). First whole genome based microsatellite DNA marker database of tomato for mapping and variety identification. BMC Plant Biology 13:197.

Mazzucato A, Papa R, Bitocchi E, Mosconi P, Nanni L, Negri V, Picarella ME, Siligato F, Soressi GP, Tiranti B, Veronesi F (2008). Genetic diversity, structure and marker-trait associations in a collection of Italian tomato (Solanum lycopersicon L.) landraces. Theoretical and Applied Genetics 116:657-669.

Miller JC, Tanksley SD (1990). RFLP analysis of phylogenetic relationships and genetic variation in the genus Lycopersicon. Theoretical and Applied Genetics 80:437-448.

Miskoska-Milevska E, Popovski ZT, Dimitrovska BR, Porcu KD (2011). Izolation of DNA for fragment analyses from tomato leaves and seeds. Conference of biotechnology with international participation. Faculty of Agronomy, Čačak, Serbia 16(18):59-64.

Miskoska-Milevska E, Dimitrovska BR, Popovski ZT (2012). Optimization of PCR condition to amplify DNA microsatellites in tomato (Lycopersicon esculentum Mill.). International Symposium for Agriculture and Food, Faculty of Agricultural Sciences and Food, Skopje, Macedonia, pp 626-634.

Miskoska-Milevska E, Popovski TZ, Dimitrievska RB, Bandzo K (2015). DNA microsatellite analyses for tomato genetic differentiation. Genetika 47(3):1123-1130.

Nei M (1987). Molecular evolutionary genetics. Columbia University Press, New York.

Ohta T, Kimura M (1973). A model of mutation appropriate to estimate the number of electrophoretically detectable alleles in a finite population. Genetics Research 22:201-204.

Smulders MJM, Bredemeijer G, Rus-Kortekaas W, Arens P, VosmanB (1997). Use of short microsatellites from database sequences to generate polymorphisms among Lycopersicon esculentum cultivars and accessions of their Lycopersicon species. Theoretical and Applied Genetics 97:264-272.

Villalta I, Reina-Sánchez A, Cuartero J, Carbonell AE, Asins MJ (2005). Comparative microsatellite likage analysis and genetic structure of two populations of $\mathrm{F}_{6}$ lines derived from Lycopersicon pimpinellifolium and L. cheesmanii. Theoretical and Applied Genetics 110:881-894.

Vosman B, Cooke R, Ganal M, Peeters R, Isaac P, Bredemeijer G (2001). Standardization and application of microsatellite markers for variety identification in tomato and wheat. Acta Horticulturae 546:307-311.

Weber JL, Wong C (1993) Mutation of human short tandem repeats. Human Molecular Genetics 2:1123-1128. 